\title{
Convective heat transfer coefficient for indoor forced convection drying of vermicelli
}

\author{
Ravinder Kumar Sahdev ${ }^{1}$, Nitesh Jain ${ }^{1}$ and Mahesh kumar ${ }^{2}$ \\ ${ }^{1}$ (Department of Mechanical Engineering, University Institute of Engineering \& Technology, Maharshi Dayanand University, \\ Rohtak, India) \\ ${ }^{1}$ (Department of Mechanical Engineering, University Institute of Engineering \& Technology, Maharshi Dayanand University, \\ Rohtak, India) \\ ${ }^{2}$ (Department of Mechanical Engineering, Guru Jambheshwar University of Sciences \& Technology, Hisar, India)
}

\begin{abstract}
In this present research paper, an attempt has been made to determine the convective heat transfer coefficient of vermicelli under indoor forced convection drying mode. The experiments were conducted in the month of March 2012 in

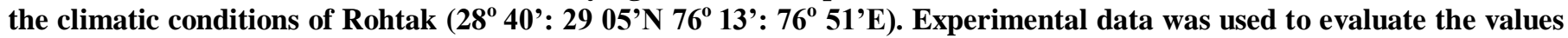
of constants $(C$ and $n$ ) in Nusselt number expression by using linear regression analysis and consequently convective heat transfer coefficients were determined. The convective heat transfer coefficient values for vermicelli were found to vary from 0.98 to $1.10 \mathrm{~W} / \mathrm{m}^{20} \mathrm{C}$. The experimental error in terms of percent uncertainty has also been calculated.
\end{abstract}

Keywords: - Convective heat transfer coefficient, Indoor forced convection drying, Vermicelli.

\section{NOMENCLATURE}

$A_{t} \quad$ area of rectangular wire mesh tray, $\mathrm{m}^{2}$

C constant

$C_{v} \quad$ specific heat of humid air, $\mathrm{J} / \mathrm{kg}{ }^{\circ} \mathrm{C}$

$h_{c} \quad$ convective heat transfer coefficient, $\mathrm{W} / \mathrm{m}^{2}{ }^{\circ} \mathrm{C}$

$h_{c, a v} \quad$ average convective heat transfer coefficient, $\mathrm{W} / \mathrm{m}^{2}{ }^{\circ} \mathrm{C}$

$K_{v} \quad$ thermal conductivity of humid air, $\mathrm{W} / \mathrm{m}^{\circ} \mathrm{C}$

$m_{e v} \quad$ moisture evaporated, $\mathrm{kg}$

$n \quad$ constant

$\mathrm{Nu} \quad$ Nusselt number $=h_{c} X / K_{v}$

Pr Prandtl number $=\mu_{v} C_{v} / K_{v}$

$\operatorname{Re} \quad$ Reynolds number $=\rho V X / \mu$

$P(T)$ partial vapor pressure at temperature $T, \mathrm{~N} / \mathrm{m}^{2}$

$Q_{e} \quad$ rate of heat utilized to evaporate moisture, $\mathrm{J} / \mathrm{m}^{2} \mathrm{~s}$

$t \quad$ time, s

$T_{v} \quad$ vermicelli surface temperature, ${ }^{\circ} \mathrm{C}$

$T_{e} \quad$ temperature just above vermicelli surface, ${ }^{\circ} \mathrm{C}$

$\overline{T_{v}} \quad$ average vermicelli surface temperature, ${ }^{\circ} \mathrm{C}$

$\bar{T}_{e} \quad$ average temperature of humid air, ${ }^{\circ} \mathrm{C}$

$T_{i} \quad$ average of vermicelli surface and humid air temperature, ${ }^{\circ} \mathrm{C}$

$X \quad$ characteristic dimension, $\mathrm{m}$

$V \quad$ air velocity, $\mathrm{m} / \mathrm{s}$ 
IOSR Journal of Engineering

June. 2012, Vol. 2(6) pp: 1282-1290

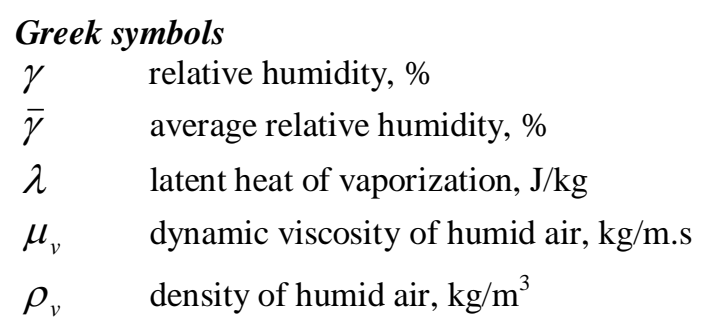

\section{INTRODUCTION}

Vermicelli is a traditional food item which is prepared in household level by extruding the dough (wheat semolina with suitable quantity of water contents) with a cylindrical hand extruder. The extruded product is dried by different means. Open sun drying is the most primitive methods of vermicelli drying. The removal of moisture from the interior of the vermicelli takes place due to induced vapor pressure difference between the vermicelli and surrounding medium.

The convective heat transfer coefficient is an important parameter in drying rate simulation since the temperature difference between the air and vermicelli varies with this coefficient. Sodha et al. [1] presented a simple analytical model based on simultaneous heat and mass transfer at the product surface and included the effect of wind speed, relative humidity, product thickness, and heat conducted to the ground for open sun drying and for a cabinet dryer. Goyal and Tiwari [2] have studied heat and mass transfer in product drying systems and have reported the values of convective heat transfer coefficient for wheat and gram as 12.68 and $9.62 \mathrm{~W} / \mathrm{m}^{2}{ }^{\circ} \mathrm{C}$, respectively, by using the simple regression and 9.67 and $10.85 \mathrm{~W} / \mathrm{m}^{2}{ }^{\circ} \mathrm{C}$ respectively, for same products while using the multiple regression technique. Anwar and Tiwari [3] studied the drying of six crops (green chilies, green peas, white gram, onion flakes, potato slices and cauliflower) under forced convection drying mode. The values of convective heat transfer coefficients were found to vary between 1.31 and $12.80 \mathrm{~W} / \mathrm{m}^{2}{ }^{\circ} \mathrm{C}$ and between 1.25 and $10.94 \mathrm{~W} / \mathrm{m}^{20} \mathrm{C}$ in indoor open and closed conditions under forced mode respectively. Akpinar [4] determined the convective heat transfer coefficient of various agricultural products, namely, mulberry, strawberry, apple, garlic, potato, pumpkin, eggplant, and onion under indoor forced convection drying mode. The convective heat transfer coefficient of these crops was found to vary from crop to crop between $0.644-7.121 \mathrm{~W} / \mathrm{m}^{2}{ }^{\circ} \mathrm{C}$. Togrul $[5,6]$ have determined the convective heat transfer coefficients of some crops dried under open sun conditions. Kumar et al. [7] studied the drying of papad in open sun and indoor forced convection drying modes. The convective heat transfer coefficients of papad were found to be 3.54 and $1.56 \mathrm{~W} / \mathrm{m}^{2}{ }^{\circ} \mathrm{C}$ under open sun drying and indoor forced convection drying modes respectively.

In the present research paper, the convective heat transfer coefficients have been found for vermicelli of diameter $2 \mathrm{~mm}$ dried under indoor forced convection drying mode. These values would be helpful in designing a dryer to dry vermicelli to its optimum storage moisture level of about $9 \%$.

\section{EXPERIMENTAL SET-UP AND PROCEDURE}

A rectangular shaped wire mesh tray of dimension $196 \times 155 \mathrm{~mm}^{2}$ was used to accommodate the vermicelli. A digital weighing balance (Smart, Aqua Series) of $6 \mathrm{~kg}$ capacity having a least count of $0.1 \mathrm{~g}$ was used to measure the mass of moisture evaporated. A non-contact (infra-red thermometer) thermometer (Raytek-MT4) having a least count of $0.2{ }^{\circ} \mathrm{C}$ with an accuracy of $\pm 2 \%$ on a full scale range of -1 to $400{ }^{\circ} \mathrm{C}$ was used to measure the surface temperature of vermicelli. An eight channel digital temperature indicator $\left(0-200^{\circ} \mathrm{C}\right.$, least count of $\left.0.1{ }^{\circ} \mathrm{C}\right)$ with a calibrated thermocouple was used to measure the ambient temperature. A digital hygrometer (model Lutron HT-315) was used to measure the relative humidity and temperature of exit air. A heat convector (Usha Shriram, model FH-812T, 230V) was used to blow hot air over the vermicelli surface during the forced convection mode.

Experiments were conducted in the month of March 2012 for indoor forced convection drying mode in the climatic conditions of Rohtak ( $\left.28^{\circ} 40^{\prime}: 2905^{\prime} \mathrm{N} 76^{\circ} 13^{\prime}: 76^{\circ} 51^{\prime} \mathrm{E}\right)$. The vermicelli was kept on the weighing balance using the wire mesh tray. A digital hygrometer was kept after vermicelli surface with its probe facing the exit air to measure the humidity and temperature of the exit air. Every time it was kept on 1 minute before reading the observations. The air velocity of heat convector was measured with the help of digital anemometer (model Lutron AM-4201) and it was observed to be $1.5 \mathrm{~m} / \mathrm{s}$. All the observations were recorded at every 5 minute time interval. The difference in weight directly gave the quantity of water evaporated during that time interval. Average values of vermicelli surface temperature $\left(\overline{T_{v}}\right)$, exit air temperature $\left(\overline{T_{e}}\right)$ and relative humidity $(\bar{\gamma})$ were calculated from the two consecutive values for that time interval and were used in the calculations. The photograph of the experimental set up under indoor forced convection drying mode is shown in Fig. 1. The experiment was repeated twice for obtaining more accurate results. 


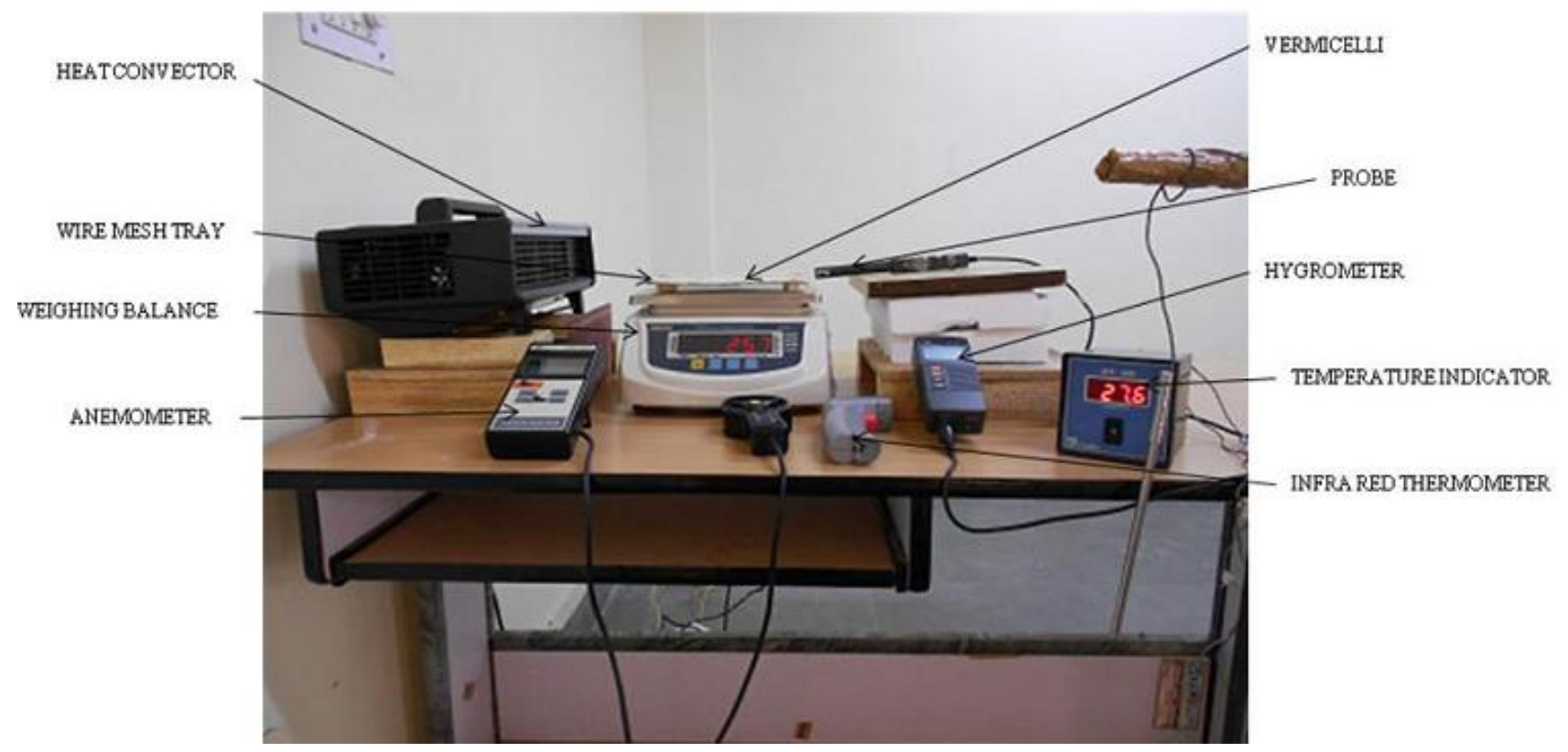

Figure 1: A photograph of experimental set-up for indoor forced convection drying mode

\section{SAMPLE PREPARATION}

Vermicelli was freshly prepared by taking wheat semolina flour mixed with $30 \%$ of water content per $\mathrm{kg}$ of vermicelli weight. The flour was purchased locally, and that fraction of flour which passes through a 40-mesh sieve (610 microns) was used for making vermicelli. Dough was made and extruded in cylindrical hand extruder of $59 \mathrm{~mm}$ diameter and $118 \mathrm{~mm}$ height (Fig. 2). The bottom of extruder is attached with steel die plates of $57 \mathrm{~mm}$ diameter having holes of $2 \mathrm{~mm}$ diameter (Fig. 3). The freshly prepared vermicelli of 25.7 grams and 24.5 grams of $2 \mathrm{~mm}$ diameter respectively were used for indoor forced convection drying mode.

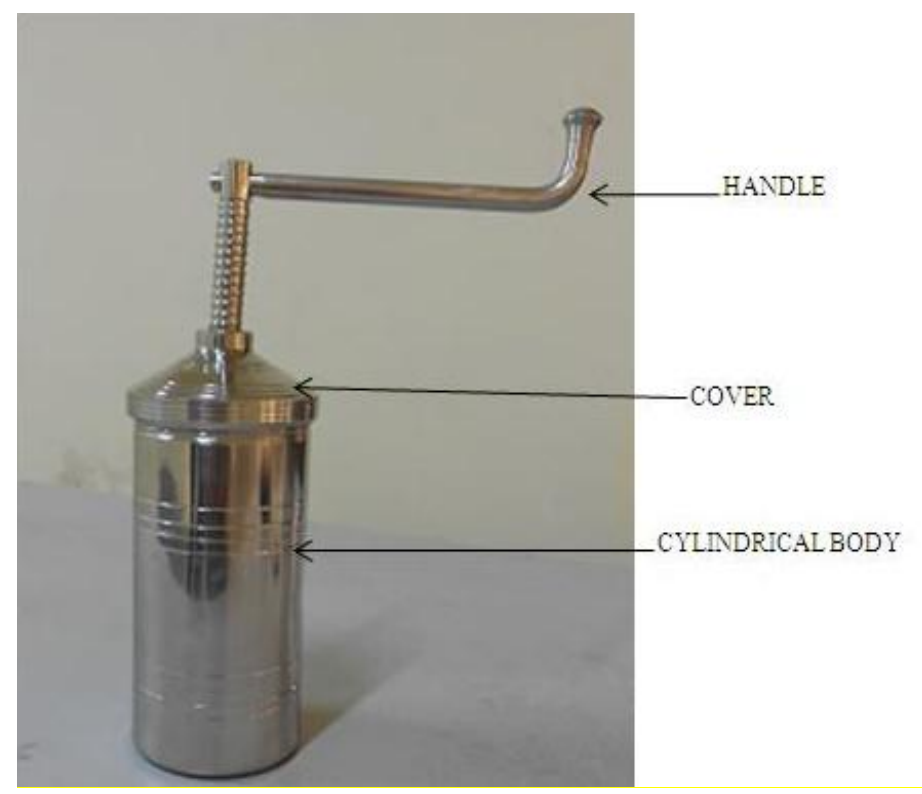

Figure 2: A photograph of cylindrical hand extruder 


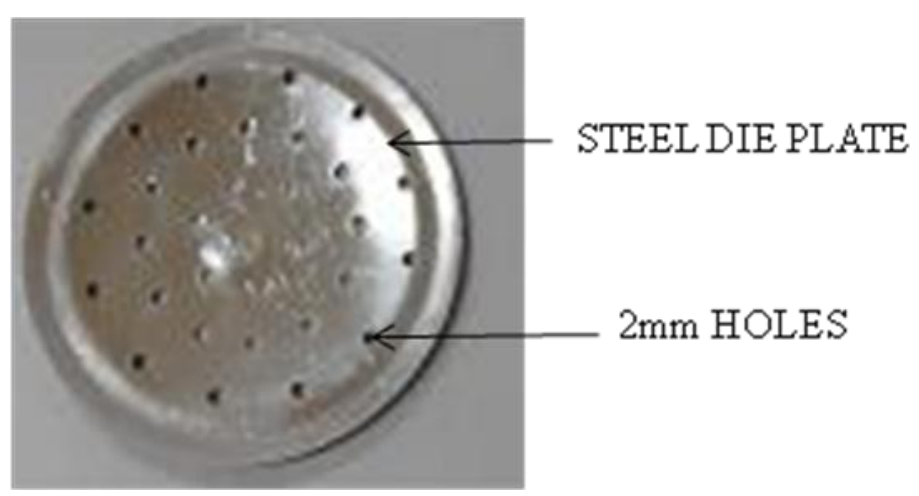

Figure 3: A photograph of Steel die plate

\section{THERMAL MODELING}

The convective heat transfer coefficient for indoor forced convection drying mode has been calculated by using the expression for Nusselt number as [7, 8]:

$: N u=\frac{h_{c} X}{K_{v}}=C(\operatorname{Re} \operatorname{Pr})^{n}$

Or

$: h_{c}=\frac{K_{v}}{X} C(\operatorname{Re} \operatorname{Pr})^{n}$

The rate of heat utilized to evaporate moisture is given as [9]

$: Q_{e}=0.016 h_{c}\left[P\left(T_{v}\right)-\gamma P\left(T_{e}\right)\right]$

On substituting $h_{c}$ from equation (1), equation (2) becomes

$: Q_{e}=0.016 \frac{K_{v}}{X} C(\operatorname{Re} \operatorname{Pr})^{n}\left[P\left(T_{v}\right)-\gamma P\left(T_{e}\right)\right]$

The moisture evaporated is determined by dividing equation (3) by the latent heat of vaporization $(\lambda)$ and multiplying by the area of the tray $\left(A_{t}\right)$ and time interval $(t)$

$: m_{e v}=\frac{Q_{e}}{\lambda} t A_{t}=0.016 \frac{K_{v}}{X \lambda} C(\operatorname{Re} \operatorname{Pr})^{n}\left[P\left(T_{v}\right)-\gamma P\left(T_{e}\right)\right] t A_{t}$

Let: $0.016 \frac{K_{v}}{X \lambda}\left[P\left(T_{v}\right)-\gamma P\left(T_{e}\right)\right] t A_{t}=Z$

$: \frac{m_{e v}}{Z}=C(\operatorname{Re} \operatorname{Pr})^{n}$

Taking logarithm on both sides of equation (5)

$: \ln \left[\frac{m_{e v}}{Z}\right]=\ln C+n \ln (\operatorname{Re} \operatorname{Pr})$ 
This is the form of a linear equation,

$: Y=m X_{0}+C_{0}$

Where

$: Y=\ln \left[\frac{m_{e v}}{Z}\right], \quad: m=n, \quad: X_{0}=\ln (\operatorname{Re} \operatorname{Pr}), \quad: C_{0}=\ln C$

Thus, : $C=e^{C_{0}}$

The experimental constants ( $C$ and $n$ ) were obtained from the above equations which were further used to determine the convective heat transfer coefficient.

The physical properties of humid air, i.e., specific heat $\left(C_{v}\right)$, thermal conductivity $\left(K_{v}\right)$, density $\left(\rho_{v}\right)$, viscosity $\left(\mu_{v}\right)$ and partial vapor pressure were calculated using the following expressions [10, 7]:

$: C_{v}=999.2+0.1434 T_{i}+1.101 \times 10^{-4} T_{i}^{2}-6.7581 \times 10^{-8} T_{i}^{3}$

$: K_{v}=0.0244+0.7673 \times 10^{-4} T_{i}$

$: \rho_{v}=\frac{353.44}{T_{i}+273.15}$

$: \mu_{v}=1.718 \times 10^{-5}+4.620 \times 10^{-8} T_{i}$

$: P(T)=\exp \left[25.317-\frac{5144}{(T+273.15)}\right]$

Where

$: T_{i}=\frac{\bar{T}_{v}+\bar{T}_{e}}{2}$

The values of constants $\mathrm{C}$ and $\mathrm{n}$ have been determined by linear regression analysis by using measured data of the vermicelli and exit air temperature, exit air relative humidity and moisture evaporated during a certain time period. The following linear regression formulae have been used to calculate $C$ and $n$

$: n=\frac{N_{o} \sum X_{0} Y-\sum X_{0} \sum Y}{N_{o} \sum X_{0}^{2}-\left(\sum X_{0}\right)^{2}}$

And

$: C_{0}=\frac{\sum X_{0}^{2} \sum Y-\sum X_{0} \sum X_{0} Y}{N_{o} \sum X_{0}^{2}-\left(\sum X_{0}\right)^{2}}$ 
The experimental error were also calculated in terms of \% uncertainty (internal + external). The following equations were used to evaluate \% uncertainty [11].

$: U=\frac{\sqrt{\sigma_{1}^{2}+\sigma_{2}^{2}+\sigma_{3}^{2} \ldots+\sigma_{n}^{2}}}{N}$

Where $\sigma$ is the standard deviation and is given as

$: \sigma=\sqrt{\frac{\sum\left(X_{i}-\bar{X}_{i}\right)^{2}}{N_{0}}}$

Where $X_{i}$ is the moisture evaporated and $\left(X_{i}-\bar{X}_{i}\right)$ is the deviation of the observations from the mean. $N$ and $N_{o}$ are the number of sets and number of observations in each set, respectively.

The $\%$ uncertainty was determined using the following expression.

$: \%$ internal uncertainty $=\frac{U}{\text { Average of total number of observations }} \times 100$

\section{EXPERIMENTAL RESULTS AND DISCUSSION}

The values of observations for indoor forced convection drying mode are recorded in Tables 1 and 2 for vermicelli of 2 mm diameter.

TABLE 1

Observations for vermicelli under indoor forced convection drying mode (Set1:28-03-2012)

\begin{tabular}{|c|c|c|c|c|c|c|c|c|}
\hline $\begin{array}{l}\text { Drying time } \\
\text { (min.) }\end{array}$ & $\mathrm{Wt}(\mathrm{gms})$ & $T_{v}\left({ }^{o} C\right)$ & $T_{e}\left({ }^{o} C\right)$ & $\gamma(\%)$ & $\mathrm{m}_{\mathrm{ev}}(\mathrm{gm})$ & $\overline{T_{v}}\left({ }^{o} C\right)$ & $\overline{T_{e}}\left({ }^{o} C\right)$ & $\bar{\gamma}(\%)$ \\
\hline 0 & 25.7 & 31.7 & 33.18 & 0.3225 & - & - & - & - \\
\hline 5 & 24.4 & 35.2 & 34.99 & 0.2805 & 1.3 & 33.4 & 34.09 & 0.3015 \\
\hline 10 & 23.5 & 37.1 & 35.57 & 0.2642 & 0.9 & 36.1 & 35.28 & 0.2724 \\
\hline 15 & 22.8 & 38.4 & 35.90 & 0.2619 & 0.7 & 37.8 & 35.74 & 0.2631 \\
\hline 20 & 22.3 & 38.7 & 36.25 & 0.2550 & 0.5 & 38.6 & 36.08 & 0.2585 \\
\hline 25 & 21.9 & 39.1 & 36.18 & 0.2531 & 0.4 & 38.9 & 36.22 & 0.2541 \\
\hline 30 & 21.5 & 39.4 & 36.11 & 0.2525 & 0.4 & 39.3 & 36.15 & 0.2528 \\
\hline 35 & 21.2 & 39.5 & 36.43 & 0.2493 & 0.3 & 39.5 & 36.27 & 0.2509 \\
\hline 40 & 20.9 & 39.7 & 36.53 & 0.2482 & 0.3 & 39.6 & 36.48 & 0.2488 \\
\hline 45 & 20.7 & 41.1 & 36.78 & 0.2432 & 0.2 & 40.4 & 36.66 & 0.2457 \\
\hline 50 & 20.5 & 39.8 & 36.44 & 0.2461 & 0.2 & 40.4 & 36.61 & 0.2447 \\
\hline 55 & 20.3 & 39.7 & 36.40 & 0.2482 & 0.2 & 39.7 & 36.42 & 0.2472 \\
\hline 60 & 20.1 & 39.9 & 36.46 & 0.2457 & 0.2 & 39.8 & 36.43 & 0.2470 \\
\hline 65 & 19.9 & 40.0 & 36.31 & 0.2485 & 0.2 & 40.0 & 36.39 & 0.2471 \\
\hline
\end{tabular}


TABLE 2

Observations for vermicelli under indoor forced convection drying mode (Set2:29-03-2012)

\begin{tabular}{|c|c|c|c|c|c|c|c|c|}
\hline $\begin{array}{l}\begin{array}{l}\text { Drying time } \\
\text { (min.) }\end{array} \\
\end{array}$ & $\mathrm{Wt}$ (gms) & $T_{v}\left({ }^{o} C\right)$ & $T_{e}\left({ }^{o} C\right)$ & $\gamma(\%)$ & $\mathrm{m}_{\mathrm{ev}}(\mathrm{gm})$ & $\overline{T_{v}}\left({ }^{o} C\right)$ & $\overline{T_{e}}\left({ }^{o} C\right)$ & $\bar{\gamma}(\%)$ \\
\hline 0 & 24.5 & 31.48 & 30.98 & 0.3640 & - & - & - & - \\
\hline 5 & 23.1 & 34.70 & 33.40 & 0.3150 & 1.4 & 33.1 & 32.19 & 0.3395 \\
\hline 10 & 22.2 & 35.35 & 33.75 & 0.3029 & 0.9 & 35.0 & 33.58 & 0.3090 \\
\hline 15 & 21.6 & 36.43 & 34.45 & 0.2917 & 0.6 & 35.9 & 34.10 & 0.2973 \\
\hline 20 & 21.1 & 36.78 & 34.17 & 0.2953 & 0.5 & 36.6 & 34.31 & 0.2935 \\
\hline 25 & 20.7 & 37.45 & 33.76 & 0.2998 & 0.4 & 37.1 & 33.97 & 0.2976 \\
\hline 30 & 20.3 & 37.80 & 33.89 & 0.2984 & 0.4 & 37.6 & 33.83 & 0.2991 \\
\hline 35 & 20.0 & 37.75 & 33.90 & 0.2963 & 0.3 & 37.8 & 33.90 & 0.2974 \\
\hline 40 & 19.7 & 37.85 & 34.36 & 0.2907 & 0.3 & 37.8 & 34.13 & 0.2935 \\
\hline 45 & 19.5 & 37.58 & 34.66 & 0.2905 & 0.2 & 37.7 & 34.51 & 0.2906 \\
\hline 50 & 19.3 & 38.23 & 34.47 & 0.2865 & 0.2 & 37.9 & 34.57 & 0.2885 \\
\hline 55 & 19.1 & 38.28 & 34.72 & 0.2827 & 0.2 & 38.23 & 34.60 & 0.2846 \\
\hline 60 & 18.9 & 38.40 & 34.59 & 0.2822 & 0.2 & 38.3 & 34.66 & 0.2825 \\
\hline 65 & 18.8 & 39.50 & 34.73 & 0.2787 & 0.1 & 39.0 & 34.66 & 0.2805 \\
\hline 70 & 18.6 & 38.25 & 34.60 & 0.2784 & 0.2 & 38.9 & 34.67 & 0.2786 \\
\hline 75 & 18.5 & 38.33 & 34.60 & 0.2804 & 0.1 & 38.3 & 34.60 & 0.2794 \\
\hline 80 & 18.4 & 38.65 & 34.46 & 0.2768 & 0.1 & 38.5 & 34.53 & 0.2786 \\
\hline
\end{tabular}

The average of vermicelli surface temperature $\left(\bar{T}_{v}\right)$, exit air temperature $\left(\bar{T}_{e}\right)$ and exit air relative humidity $(\bar{\gamma})$ were used to calculate the physical properties of the humid air which were further used to evaluate the values of Reynolds number and Prandtl number. The values of ' $C$ ' and ' $n$ ' in equation (1) were obtained by simple linear regression analysis, and, thus the values of $h_{c}$ were determined as given in Table 3 .

TABLE 3

Values of $\mathrm{C}, \mathrm{n}$ and convective heat transfer coefficients

\begin{tabular}{|l|c|c|c|}
\hline Diameter $(2 \mathrm{~mm})$ & $\mathrm{C}$ & $\mathrm{n}$ & $\mathrm{h}_{\mathrm{c}}\left(\mathrm{W} / \mathrm{m}^{2}{ }^{\circ} \mathrm{C}\right)$ \\
\hline Set 1 & 1.00 & 0.21 & $1.09-1.10$ \\
\hline Set 2 & 0.99 & 0.20 & $0.98-0.99$ \\
\hline
\end{tabular}

The convective heat transfer coefficients for vermicelli under indoor forced convection drying mode have been observed to vary from 0.98 to $1.10 \mathrm{~W} / \mathrm{m}^{2}{ }^{\circ} \mathrm{C}$. This variation could be due to change in operating conditions. It can be seen from Table 3 that the convective heat transfer coefficient does not change much for both the sets. The variation of convective heat transfer coefficient with respect to time for indoor forced convection drying mode is shown in Fig. 4 and 5. 
IOSR Journal of Engineering

June. 2012, Vol. 2(6) pp: 1282-1290

1.100

1.095

1.090

1.085

○ 1.080

$\stackrel{\Xi}{\xi} 1.075$

$\begin{array}{ll}3 & 1.070 \\ - & 1.065\end{array}$

1.065

1.060

1.055

1.050

\section{$\begin{array}{llllllllllllll}5 & 10 & 15 & 20 & 25 & 30 & 35 & 40 & 45 & 50 & 55 & 60 & 65 & 70\end{array}$ \\ Time, mins}

Figure 4: $h_{c}$ vs time for vermicelli under indoor forced convection drying mode (set 1$)$

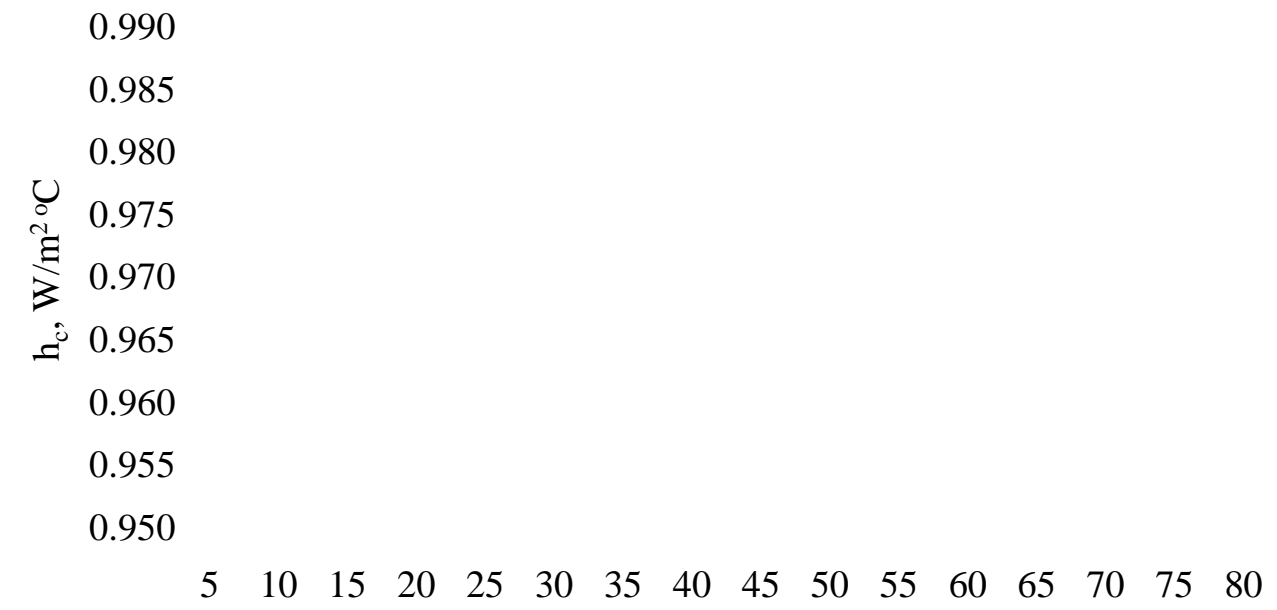

Time, mins

Figure 5: $h_{c}$ vs time for vermicelli under indoor forced convection drying mode (set 2)

The experimental errors were calculated in terms of percent uncertainty (internal + external) for the mass of water evaporated. The value of percent uncertainty (internal + external) was found to be with in $79.87 \%$.

\section{CONCLUSION}

The convective heat transfer coefficients for vermicelli under indoor forced convection drying mode were determined using the values of the constants, ' $\mathrm{C}$ ' and ' $\mathrm{n}$ ' in the Nusselt number expression by using the linear regression technique. The convective heat transfer coefficients were observed to vary from 0.98 to $1.10 \mathrm{~W} / \mathrm{m}^{2}{ }^{\circ} \mathrm{C}$. The experimental errors were found to be within $79.87 \%$. 


\section{REFERENCES}

[1] M.S. Sodha, A. Dang, P.K. Bansal and S.B. Sharma, An analytical and experimental study of open sun drying and a cabinet type dryer. Energy Conversion and Management, 25, 1985, 263-271.

[2] R.K. Goyal and G.N. Tiwari, Heat and mass transfer relations for crop drying, Drying Technology, 16(8), 1998, 17411754.

[3] S.I. Anwar and G.N. Tiwari, Convective heat transfer coefficient of crops in forced convection drying - an experimental study, Energy conversion and management, 42(14), 2001a, 1687-1698.

[4] E.K. Akpinar, Experimental investigation of convective heat transfer coefficient of various agricultural products under open sun drying, International Journal of Green Energy, 1(4), 2004, 429-440.

[5] I.T. Togrul, Determination of convective heat transfer coefficient of various crops drying under open sun drying conditions, International Communication Heat Mass Transfer,30(2), 2003, 285-294.

[6] I.T. Togrul, Convective heat transfer coefficient of apricots under open sun drying conditions, Chemical Engineering Communications, 192(8), 2005, 1036-1045.

[7] M. Kumar, P. Khatak, R. K. Sahdev and O. Prakash, The effect of open sun and indoor forced convection on heat transfer coefficients for the drying of papad, Journal of energy in South Africa, 22(2), 2011, 40-46.

[8] G.N. Tiwari and S. Suneja, Solar thermal engineering systems (Narosa Publication House, New Delhi: 1997).

[9] M.A.S. Malik, G.N. Tiwari, A. Kumar and M.S. Sodha, Solar Distillation (Pergamon Press, Oxford: 1982).

[10] S.I. Anwar and G.N. Tiwari, Evaluation of convective heat transfer coefficient in crop drying under open sun drying conditions, Energy conversion and management, 42(5), 2001b, 627-637.

[11] B.C. Nakra and K.K. Choudhary, Instrumentation, measurement and analysis (Tata McGraw- Hill Publishing Co, New Delhi: 1991). 